\title{
Um incentivo aos sábios: os sócios do Instituto Histórico e Geográfico Brasileiro e o projeto de centralização monárquica (1839-1850)
}

\author{
An incentive to the wise ones: the members of IHGB and the centralinzing project
}

monarch (1839-1850)

\author{
Raphael Silva Fagundes \\ Doutorando \\ Universidade do Estado do Rio de Janeiro \\ raphaelsfagundes@yahoo.com.br
}

\begin{abstract}
Resumo: Buscaremos destacar o empenho dos membros do Instituto Histórico Geográfico Brasileiro na construção da imagem de si e de seus confrades. Os discursos analisados tinham como principal objetivo incentivar os membros do Instituto à pesquisa na composição da história nacional. No entanto, a retórica ao redor dessa imagem daria a tais eruditos a legitimidade do discurso sobre a nação, o monopólio de sua definição. Ao analisar a retórica dos discursos pronunciados nas sessões magnas de aniversário da associação, podemos observar como tais literatos, protegidos por Sua Majestade o Imperador D. Pedro II, buscavam construir a autoimagem de indivíduos indispensáveis para o progresso da nação e para o sucesso do projeto centralizador inaugurado com o Golpe da Maioridade. Palavras-chave: IHGB, retórica, Império do Brasil.
\end{abstract}

\begin{abstract}
We will try to highlight the effort of members of the IHGB in building the image of themselves and their colleagues. The speeches analyzed had as main objective to encourage the members of the institute to the research in the composition of national history. However, the rhetoric around that image would give such scholars the legitimacy of the discourse on the nation, the monopoly of its definition. When analyzing the rhetoric utilized in speeches delivered on the magna sessions of the anniversary of the association, it is noticeable that the scholars, protected by His Majesty the Emperor D. Pedro II, were intending to build an self image of people that necessary for the progress of the nation and for the triumph of the project for Centralization of Power, which was launched with the Golpe da Maioridade.
\end{abstract}

Keywords: IHGB, rhetoric, Empire of Brazil. 


\section{O ethos discursivo}

Os discursos dos presidentes do Instituto Histórico e Geográfico Brasileiro (IHGB) serão o nosso foco. Fundado em 1838 por figuras importantes do circuito político do Império, a "Casa da Memória Nacional” foi um grande reduto da erudição brasileira do século XIX, e tinha como objetivo inicial coligir documentos úteis para a história nacional. Na primeira década de sua existência a produção de discursos vinculados aos interesses da consolidação monárquica foi expressiva. $\mathrm{O}$ envolvimento de algumas destas figuras, no período da Independência, em movimentos destoantes ao projeto de estado defendido pelo IHGB nos anos $1840 \mathrm{fez}$ com que a história imediata fosse "esquecida". Acontecimentos recentes não foram submetidos ao rigor da historiografia, foram coligidos, mas não publicados. Deixaram para o Tribunal da Posteridade. (GUIMARÃES, 2011: 89) No entanto, essa história recente chegava à Casa de outra forma; por meio dos discursos pronunciados pelos presidentes no limiar das cerimônias de aniversário da associação. As desavenças que assolavam o Império eram um grande ingrediente nas palavras dos oradores que se debruçaram em uma retórica da nacionalidade que, no entender de Temístocles Cezar, buscava tanto conter e resistir à possível dispersão de um discurso, que se pretendia unívoco, quanto procurava, por meio de seus associados, constituir-se como campo de saber, voltado para explicar a existência de uma nação ao longo do tempo formada por "brasileiros" (CEZAR, 2006: 29).

A habilidade retórica, a estilística e a clareza narrativa eram de vital importância para um historiador. Laura Nogueira Oliveira demonstra que Francisco Adolfo de Varnhagen possuía três preceitos básicos para o historiador. Ele deve ser erudito, filósofo e literato. É neste último preceito que a autora destaca como Varnhagen “atualizava, a seu modo, em seus textos, práticas discursivas prescritas e revisadas desde a Antiguidade Clássica" (OLIVEIRA, 2007: 20). Para o historiador oitocentista, quem se dedicava a escrever a história deveria "aproximar o seu estilo do "estilo dos oradores de tribuna",, além de se preocupar com o belo e com a elegância. Era necessário que o leitor "desejasse prosseguir" com a leitura, "convencê-lo da exatidão narrativa" (OLIVEIRA, 2007: 84). Isto é, o projeto de se forjar uma identidade nacional através de uma perspectiva histórica ligada à centralização monárquica dependia da retórica. 
A atividade retórica dos membros do Instituto dedicava-se, entre outras questões, à construção do ethos, isto é, à imagem que o orador cria de si no discurso, e que, nessa ocasião, tinha como meta assegurar aos membros do grêmio carioca o monopólio legítimo sobre a história nacional. O ethos foi problematizado por Aristóteles que o denomina como uma das provas fornecidas pelo discurso (ao lado do logos e do pathos) e consiste no "caráter moral do orador" (ARISTOTELES, s/d: 34). Recentemente a questão do ethos foi revisitada por Dominique Maingueneau que o compreende como a personalidade que o autor exprime através do discurso (MAINGUENEAU, 2001: 137). Uma imagem de confiança, digna de fé que o orador cria em consonância com os valores e saberes compartilhados pelo auditório.

“O orador constrói sua própria imagem em função da imagem que ele faz de seu auditório, isto é, das representações do orador confiável e competente que ele crê ser as do público" (AMOSSY, 2005: 124). Essa estratégia utilizada pelo ethos, explanada por Ruth Amossy, permite-nos compreender que a representação de quem fala é feita a partir dos anseios e expectativas de quem ouve, criando respostas e, sobretudo, tornando-se referência. Além disso, estes discursos são atos de linguagem que buscam interferir diretamente na cena política que habituam. Desta forma, ficamos com a posição de Patrick Charaudeau, de que "não existe um ato de linguagem que não passe pela construção de uma imagem de si” (CHARAUDEAU, 2006: 124).

O ethos do historiador oitocentista foi muito bem capturado por Rodrigo Turin, que por meio de Silvio Romero salienta que no século XIX dominavam três topoi que forneciam os elementos para a construção da imagem do pesquisador: a sinceridade, a cientificidade e a instrumentalidade (TURIN, 2009:14-19). No entanto, como demonstra Turin ao longo de seu artigo, outros elementos fundamentais fazem parte da construção retórica da imagem do erudito publicista dedicado à causa da pátria: sua imagem de cidadão prestativo deveria servir como exemplo para as gerações futuras em termos morais. Além disso, como assegura Maria da Glória de Oliveira, determinados argumentos epistemológicos eram comuns para caracterizar o trabalho dos historiadores como a virtude, a justiça e a imparcialidade (OLIVEIRA, 2010: 291).

Mas a ideia era o de atrair cada vez mais um número maior de adeptos a causa defendia pelo IHGB, e o ethos dos membros foi fundamental para tal objetivo. Como destaca Armelle Enders, "o exemplo do grande homem deve ser contagioso, fazer surgir novos exemplos ou, ao menos, de guia moral ou cívico" (ENDERS, 2000: 46). 
Sendo assim, o sentimento pátrio, o domínio técnico-científico, o "amor à verdade", a retórica estético-afetiva e a governabilidade foram triviais para uma imagem perfeita do erudito imbuído no progresso da jovem nação. Estes elementos serão encontrados, dentre outros, na oratória dos membros do IHGB empenhados em construir a reputação da associação.

Quanto mais estreita a relação que um integrante do Instituto tinha com o Estado, mais credibilidade tinha ao falar. É o caso de José Feliciano Fernandes Pinheiro, o visconde de São Leopoldo, único sócio-fundador do IHGB que possuía um título de nobreza, não por acaso escolhido primeiro presidente da associação. É preciso destacar que, no ato de fundação do Instituto, em 1838, entre os sócios de atuação política, São Leopoldo era o único senador do Império, como mostra o levantamento realizado pela professora Lucia Maria Paschoal Guimarães (GUIMARÃES, 2011: 72). Antes de se tornar visconde cumpriu uma trajetória política extremamente significativa. Começou como juiz de alfândega no Rio de Janeiro, em seguida participou como auditor geral das tropas do exército imperial nas campanhas pacificadoras em 1811 ao sul das fronteiras, atuou como deputado nas cortes de Lisboa e na assembleia constituinte em 1823, além disso, galgaria o posto de presidente da província do Rio Grande do Sul. A sua experiência "acumulada nos quadros da administração política seria considerada decisiva para credenciá-lo à sua vocação mais genuína de historiador e 'homem de ciência"” (OLIVEIRA, 2010: 40). Era um fato comum em nossa monarquia o de um indivíduo provido de "boa" trajetória política se tornar um grande homem de letra. $\mathrm{O}$ próprio visconde deixa isso claro, ao destacar os componentes do quadro social do Instituto, "cujo renome e reputação serviriam de incentivo para nossos novos esforços" (SÃO LEOPOLDO, 1842: 02). Nesse momento não podemos deixar de citar Quintiliano, ao constatar que o processo persuasivo depende da "autoridade de quem narra” (QUINTILIANO, 1788: 162).

$\mathrm{Na}$ ocasião do primeiro aniversário do Instituto Histórico, São Leopoldo apodera-se de uma estratégia argumentativa que também seria usada por Aureliano Coutinho no ano seguinte, contudo há uma mudança nos actantes: enquanto Aureliano discursava para o Imperador, o primeiro presidente do Instituto direcionava suas palavras aos seus confrades:

Elevado a esta cadeira pelos sufrágios de vossa generosa benevolência, antes do que pela minha própria valia, confundo-me todas as vezes que me 
contemplo presidindo a uma associação por tantos títulos recomendados, seja pela sublimidade dos assuntos, que tomou por empresa, seja pelas ilustrações nacionais e estrangeiras (SÃO LEOPOLDO, 1908: 209).

Em seguida São Leopoldo irá dizer: "De minha parte, pobre de merecimento para corresponder tão grandiosa escolha", referindo-se ao fato de o terem escolhido para liderar o reduto letrado. O rebaixar-se perante o auditório é usado como estratégia para dar mais evidência ao conteúdo do enunciado que, naquele instante, se tratava dos seus pares do "interessantíssimo instituto".

Era um recurso retórico comum, como podemos ver no elogio histórico feito por Manoel Ferreira Lagos, segundo secretário do Instituto, ao padre fr. José Mariano da Conceição Velloso. Ao explicar o seu direito à fala naquela homenagem destaca:

seja-me pois permitido também, no meio de tantos literatos desprender minha fraca voz; e já que ela não pode subir tão alto como a de meus colegas, reste-me ao menos a consolação de haver contribuído com o meu fraco contingente a fazer conhecido um dos mais distintos sábios Brasileiros (LAGOS, 1916: 611).

Mais a frente no seu discurso, visconde de S. Leopoldo incentiva os membros a continuar a empresa que se dedicaram, vista como uma atitude patriótica:

Prossegui com o mesmo fervor, respeitáveis cônscios, na alta missão a que vos dedicastes; difundi instrução geral pela publicação dos vossos estudos; desta arte contribuireis para o desenvolvimento e perfeição da história e da geografia, e para o crédito e glória da pátria (SÃO LEOPOLDO, 1908: 212).

\section{O templo da sabedoria e a casa dos príncipes}

Dois anos mais tarde, no terceiro aniversário da Casa da Memória Nacional, São Leopoldo, de forma ainda mais eloquente, elogia os trabalhos dos membros do Instituto. Diz que na primeira sessão magna de aniversário da associação contemplou "os espaços imensuráveis a perlustrar, as penosas explorações, às vezes à custa da existência, para 
desempenho da árdua empresa a que vos dedicastes...”. É dada a vida pela pesquisa. Esse elogio foi, segundo o próprio Visconde, "para mais excitar o sentimento de vossas próprias forças, o aguilhão do gênio, à vista da escabrosa e difícil vereda, que conduz ao templo da sabedoria, onde vos esperam os lauréis acadêmicos" (SÃO LEOPOLDO, 1841: 517-518).

Além da retórica do esforço ligada ao trabalho, o Instituto torna-se, nas palavras do presidente, o "templo da sabedoria". Para incitar os acadêmicos à pesquisa, diz-se que esse "templo da sabedoria" tinha sábios como frequentadores, o que enaltecia os associados. Estamos perante figuras retóricas; as palavras dão forma às coisas, projetando um mundo idealizado na mente dos ouvintes. O presidente do IHGB apodera-se de "um emprego que se afasta do modo normal de expressar-se e, com isso, chama a atenção" (PERELMAN e OLBRECHTS-TYTECA, 2005: 190). Conforme já mostraram os estudos da "nova retórica", uma figura só pode ser considerada argumentativa quando acarreta uma mudança de perspectiva, fazendo, não obstante, com que seu emprego pareça normal em relação às exigências da situação (PERELMAN e OLBRECHTS-TYTECA, 2005: 192). Ou seja, a expressão "templo da sabedoria" pode ser considerada uma figura argumentativa a partir do momento em que os membros conseguissem se enxergar na mesma; o que não é difícil de imaginar, já que a missão que desempenhavam era vista como sagrada em muitos casos.

Ainda no discurso pronunciado por Araújo Vianna, é possível perceber uma argumentação que busca fortificar a imagem do Instituto:

Vereis também que excelsos Príncipes, que talentos distintos e abalizados do velho e novo mundo, não se têm dedignado de se inscrever no catálogo dos Membros do Instituto, contribuindo d'est'arte para a honra e glória da corporação, e para ilustração do gênero humano (VIANNA, 1885: 03).

A presença de príncipes nas fileiras do IHGB é trabalhada nesse discurso como mais um instrumento persuasivo. Vianna dinamiza o incentivo aos associados, porque os excelsos príncipes, além de reconhecer a importância do Instituto, tornam-se membros como eles. Príncipes tornam-se sócios, ou seja, o alto escalão da sociedade compartilha das ideias do Instituto: uma questão de identidade que, articulada pela retórica, atinge o ego dos ouvintes atraindo-os ainda mais para a causa a ser defendida. Assim, para que o grupo possa ser assumido como uma unidade, um sentimento de 
identidade é forjado, visando, a partir daí, reunir e definir a coletividade em questão, entretanto, para tal, essa igualdade entre os membros, também, deve ser dita e legitimada por eles (MEYER, 2007: 140).

Michel Meyer escreve que: "Tudo o que opõe ou reúne os homens, ainda que apenas por um momento, participa desta distância que é o objeto último da retórica" (MEYER, 2007: 31). A retórica negocia a distância. Nobres e príncipes compartilham o mesmo espaço dos sócios que tinham como orientação política a monarquia constitucional. Isso dava mais vigor à empresa a qual se dedicavam.

O sangue azul da nobreza estava no IHGB. O Rei de Portugal, D. Fernando, é presenteado com o título de presidente honorário (67ª Sessão em 6 de Julho de 1841, 1841: 353). Esse cargo era dado para os membros da família real, não só brasileira, mas de outros cantos do mundo. O príncipe da Dinamarca, por sua vez, recebeu o título de sócio honorário. Em 1843 quem recebe o título de presidente honorário é o Senhor Príncipe de Joinville, porque "tende de brevemente esposar a Sereníssima Princesa a Senhora D. Francisca" (103a Sessão em 20 de Abril de 1843, 1885: 260-261), além de S. A. Real o Sr. Príncipe Conde de Aquila.

Em 1849, Cândido José de Araújo Vianna, agora como presidente da associação, na ocasião em que o Instituto ganha uma sala nas novas instalações do Paço da Cidade, honra o Imperador pelo espaço cedido, porque deu "movimento extraordinário à patriótica empresa" (212 Sessão em 15 de Dezembro de 1849, 1973: 551) que os sócios se comprometeram. Vianna, na projeção da imagem de um imperador filósofo, protetor das artes e das ciências, destaca "a solicitude com que V. M. I. incessantemente promove tudo quanto concorre para a prosperidade e esplendor da nação" (212 $2^{\mathrm{a}}$ Sessão em 15 de Dezembro de 1849, 1973: 551).

O Imperador, associado número um do Instituto, entra em cena e responde no mesmo diapasão, incentivando os eruditos com belas palavras e se coloca ao lado deles, obviamente deixando claro o seu lugar. Em resposta ao discurso de Vianna, seu antigo professor, diz o monarca: “...como primeiro sócio, e primeiro interessado no progresso do Instituto, não posso deixar de falar-vos um pouco deste estabelecimento, ou antes de sua Revista, indeclinável testemunho do que houverdes feito bem da história e geografia do Brasil” (212 a Sessão em 15 de Dezembro de 1849, 1973: 551).

Por que o Imperador se põe como o "primeiro interessado no progresso do Instituto"? Na continuação de sua resposta ao futuro marquês de Sapucaí, assinala que os membros não deviam apenas reunir "os trabalhos das gerações passadas", mas 
também os “vossos próprios". D. Pedro II queria que os sócios do Instituto investissem em projetos contemporâneos, o que permitiria que seus esforços fossem dignos “realmente dos elogios da posteridade". Essa sugestão de S. M. I., faz parte de um plano ainda maior: a preocupação com a Memória de seu governo (GUIMARÃES, 2011: 94). Aqui o soberano pretende persuadir os membros, pois, formulava argumentos que buscavam desencadear atitudes nos seus ouvintes. Assevera que os membros deveriam produzir em prol da nação por meio de força única: "não divide pois as vossas forças, o amor da ciência é exclusivo, e, concorrendo todos unidos para tão nobre, útil, e já difícil empresa, erijamos assim um padrão de glória à civilização" (212 $2^{\mathrm{a}}$ Sessão em 15 de Dezembro de 1849, 1973: 552).

Em seguida D. Pedro II afirma que uma das razões de "reunir-vos em meu palácio", foi o desejo de estar mais próximo desse projeto árduo de "descoberta" da nação e de se manter informado dos trabalhos e comissões "dos sócios que bem cumprem com os seus deveres". Finalizando, o Imperador adverte que: "Árdua é a tarefa que empreendestes, Srs., mas, por meio de vossa constância, alcançareis a palma da vitória, e as recompensas devidas aos amigos das letras, coroando tantas fadigas,

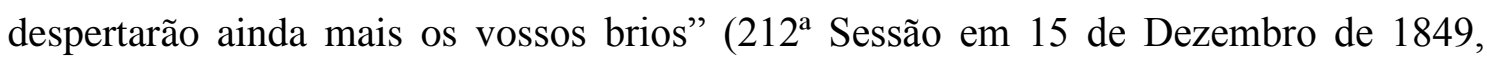
1973: 552).

Aqui o Imperador reconhece a utilidade dos trabalhos e a necessidade de recompensá-los, pois são essas gratificações, também, um incentivo ao empreendimento que deixará registrado na história a glória de seu reinado.

\section{Lapidando diamantes}

No discurso de 1842, S. Leopoldo levanta uma questão intrigante. Reitera como nos outros discursos - que o IHGB estava empenhado na construção de uma História do Brasil por meio de uma crítica severa de documentos autênticos. Mas o que queremos captar aqui é o fortalecimento dessas premissas pelo uso de metáforas nobres. Os documentos seriam coligidos e selecionados pela "escrupulosa exatidão do operário inteligente, para não confundir com o diamante o cristal rocha, e de modo lapidá-lo que brilhe, a fim de nesses exemplares espelharem-se os vindouros" (SÃO LEOPOLDO, 1842: 03). É assim que o historiador deveria lidar com suas fontes, como pedras preciosas. Os nossos letrados tinham a seguinte missão: "Propagar pelas classes menos 
ilustradas o brilhante lume que os primeiros fostes em ascender nesse continente" (SÃO LEOPOLDO, 1842: 03). Os “primeiros" são os expoentes do período colonial. Recuperar a história/memória dos ilustres de outrora era importante para se estabelecer uma continuidade com os letrados de então. Entre parênteses São Leopoldo afirma que "a nação prescinde de archotes que a fascinam e cegam; necessita de faróis que a enderecem e guiem", uma alusão ao momento político, pois as províncias de Minas Gerais e de São Paulo encontravam-se, naquele instante, sublevadas, ou seja, os "archotes" que "fascinam e cegam" a nação é uma referência aos ideais provincianos que poderiam expor o país ao desmembramento (SÃO LEOPOLDO, 1842: 04).

O uso da metáfora é muito constante, o que nos leva a destacar seu papel na argumentação. A compreensão deste recurso linguístico só ocorre em função da teoria argumentativa da analogia. A metáfora é "uma analogia condensada" (PERELMAN e OLBRECHTS-TYTECA, 2005: 453), e como dizem os tratados de retórica desde os tempos antigos, a analogia deve ser considerada um elemento de prova, apresentando-se como uma similitude de estruturas (PERELMAN e OLBRECHTS-TYTECA, 2005: 424).

A metáfora é um tropo da linguagem que busca, com o seu emprego, “ornamentar ou suavizar o nosso pensamento" (MEYER, 2007: 105). Busca-se causar um impacto maior no auditório. O objetivo é fazer ver melhor, com mais entonação aquilo que se quer mostrar, aquilo que se defende.

Para observarmos ainda mais exemplos deste fenômeno nos pronunciamentos dos sócios, cabe observar novamente o discurso de 1839 proferido pelo visconde de São Leopoldo. Em um momento de sua fala, o presidente do Instituto faz menção à Real Sociedade dos Antiquários do Norte, instituição dinamarquesa que foi uma das grandes parcerias do Instituto em âmbito internacional, permutando correspondências, artigos e diversas publicações. Esses dois redutos eruditos estreitaram seus vínculos devido à presença do naturalista Dr. Peter Wilhelm Lund, que fez grandes observações sobre a fauna e flora brasileira a partir dos anos de 1820, e também devido a um interesse mútuo entre as duas instituições: "o de encontrar provas de um passado comum, anterior a 1500. Ou seja, de demonstrar que os vikings da Escandinávia haviam chegado ou, até mesmo, povoado, o Brasil muito antes da chegada dos portugueses" (GUIMARÃES e HOLTEN, 1997: 17-19). São Leopoldo, referindo-se às descobertas sobre o passado realizadas pela Sociedade escandinava, não economiza metáforas: 
superando montes de dificuldades na infatigável investigação de inscrições de monumentos, evocando as manes gerações, que já não existem, e forçando-os a revelar fatos que derramam clarões de luz inesperada sobre uma época que parecia para sempre submergida em noite profunda. (SÃO LEOPOLDO, 1908: 209-210).

A mensagem aqui é que os "literatos" brasileiros tomem isso como exemplo. Seria possível descobrir a origem da nação por mais remota que fosse.

A metáfora é um argumento por condensar a analogia. Mas como isso funciona? Só é metáfora quando se compara realidades heterogêneas, como é o caso dos "faróis que guiam a nação" no discurso de S. Leopoldo em 1842. Os acontecimentos do passado, ou os homens ilustres, não são comparados com faróis, eles são os próprios, ou seja, há uma condensação da analogia. Da mesma forma, o que é desconhecido está em "noite profunda" e tornar evidente é "derramar clarões de luz". Não se diz que o passado é evidenciado através das pesquisas como a luz torna evidente as coisas, diz-se que elas revelam "fatos que derramam clarões de luz".

O árduo trabalho dos sócios é sempre lembrado e usado como foco de uma argumentação que pretende persuadir os ouvintes de que o labor desenvolvido na Casa, seria o mais sublime e, por sua vez, o mais eficaz para o progresso e civilização da nação. Quando Candido José de Araújo Vianna, vice-presidente do Instituto, vai discursar na sessão magna aniversária em 1843, deixa transparecer exatamente esses aspectos:

Assim é que pelas infatigáveis lucubrações de seus Membros já é dado as nossas vistas descortinar fatos, ou esquecidos ou confusos, que desde o descobrimento da terra de Santa Cruz esperam por escritores imparciais e de critérios, que os coordenem para servirem à mais ampla instrução dos homens (VIANNA, 1885: 02).

São os sábios que irão tirar da escuridão o conhecimento sobre o Brasil. E que também criarão o conhecimento verdadeiro e útil, como exigem os padrões historicistas da época. 
A retórica aqui está muito relacionada aos predicados atribuídos aos sujeitos. O Imperador é o protetor das letras e ciências e o promulgador da civilização; os membros do Instituto são os operários da inteligência com a missão de esclarecer sobre a nação para todo o universo. Contudo, somente esses predicados não seriam suficientes, precisava-se do selo da ciência. Os membros "descortinam" os fatos através de suas "lucubrações" aparentemente "imparciais" e com "critérios" de cientificidade que davam caráter de verdade, diz Vianna. Desta forma, tudo que era dito deveria estar em conexão com a noção de verdade do momento, respondendo às suas questões, pois "todo o discurso é de certa maneira um responder", um questionamento, atendendo assim as aspirações momentâneas (MEYER, 2007: 47).

$\mathrm{O}$ valor das pesquisas não emana dos seus resultados, mas dos discursos que as codificam de acordo com os interesses dos falantes. A mera investigação não poderia persuadir o Imperador de sua utilidade, nem mesmo poderia ser um projeto de glória para a nação. Eram as palavras, trabalhadas com grande destreza e conectadas aos valores e saberes da época, que davam sentido às coisas, evidenciando o que seria útil para consolidação do projeto de monarquia constitucional.

Outro investimento era na retórica ligada às expectativas futuras que, por sua vez, possuía duas vias: uma do Imperador para os sócios (como vimos); e outra dos sócios para os sócios. O visconde de São Leopoldo ainda em 1839 afirmava:

Sobretudo, senhores, ninguém ousará contestar-vos que no Instituto legais à posteridade depósito inestimável de preciosidades literárias, enxame de capacidades, seleto e esperançoso, cujo progresso fácil é de calcular, pelo quanto se tem já avantajado, com um ano apenas de existência (SÃO LEOPOLDO, 1908, 211).

Os membros do IHGB também deixarão para o futuro diamantes, isto é, documentos históricos. Esse tipo de argumentação pode ser chamada de "vínculo causal". Há um aspecto em tal técnica argumentativa que cabe destacar: "sendo dado um acontecimento, tendem a evidenciar o efeito que dele deve resultar" (PERELMAN e OLBRECHTS-TYTECA, 2005: 300). São aspectos que buscam na argumentação uma impressão de realidade que envolve o orador e o ouvinte.

Ao destacarem a proposta de fundar duas novas comissões (arqueologia e etnografia), Manoel Ferreira Lagos e Manuel de Araújo Porto-Alegre também se valem 
do "vínculo causal", enfatizando as realizações e o esplendor que o Instituto atingirá pelo que se faz no presente: “O Instituto, pela maneira tão nobre e grave com que dirige os seus passos, terá de em breves anos, com adição de outras sessões, de se tornar um corpo científico respeitável, e de formar um Instituto Imperial, digno de ser oráculo científico das duas Américas” (178 Sessão em 16 de setembro de 1847, 1869:443-4).

Esse vínculo causal pode ser um acontecimento passado que desembocou no presente ou um fato do presente, que terá consequências no futuro, dando espaço ao orador para o manuseio não só do passado e do futuro, mas também do presente, ativando um raciocínio lógico no ouvinte, no qual se destacam as mais nítidas implicações de um determinado ato. O Imperador aspirava que fossem escritos os sucessos do seu reinado, para que as gerações futuras reconhecessem a sua glória; e os sócios, por sua vez, guardavam obras e documentos em seus arquivos, para que os pesquisadores do futuro reconhecessem que foram eles os grandes guardiões do passado nacional, possibilitando um conhecimento fidedigno da nação. Como os heróis, seriam lembrados por um longo tempo. Ambos aspiravam despertar o efeito de glória, incitando os ouvintes (que no caso são os sócios do Instituto), através das palavras, a uma determinada ação. E é esse levar à ação que consiste a retórica.

\section{A civilização entre a unidade e a fé}

Por certo, é fato que os "literatos" do Instituto ouviam as palavras dos presidentes e vice-presidentes e ganhavam um estímulo a mais para agir. Todos estavam envolvidos pela mesma sensibilidade, que pretendia chegar até as regiões mais profundas do passado para se poder desvendar a glória da pátria e "fundar bases sólidas a nossa nacionalidade" (BARBOSA, 1843: 05). Esses eruditos já acolhiam em si o desejo de contribuir para isso, as palavras lançadas no ar não buscavam despertar um novo sentimento, mas apenas incrementar, nos sócios, o que neles já existia. E todo esse material era publicado na Revista do Instituto para que os leitores de todos os cantos do Brasil fossem atingidos por essa retórica, reconhecendo a função do IHGB na jovem nação tropical.

Todos esses discursos também tinham como meta possibilitar a ascensão da nação brasileira no circuito internacional. Os sábios de então sabiam que o reconhecimento de uma civilização nos trópicos era um grande problema. Promoviam- 
se muitas pesquisas, coligiam-se fontes, escreviam-se trabalhos que buscavam tornar evidente o nosso esplendor civilizacional. Entretanto, ainda havia problemas por parte das nações europeias em identificar estas terras como suas semelhantes. No discurso do vice-presidente Cândido José de Araújo Vianna, na celebração do sexto aniversário do Instituto, destaca-se este ponto: "Em verdade, Senhores, que glória não cabe aos fundadores de uma instituição, que, trabalhando em honra da pátria, fazem-na conhecida das nações estrangeiras, que, a despeito de sua adiantada civilização, ignoram ainda quase tudo de nossa história e geografia?" (VIANNA, 1973: 2)

Reconhece-se o diferente grau de civilização entre o Brasil e a Europa, porém, é glorioso o trabalho desses publicistas na busca de informações "dos nossos sucessos relacionados entre si desde a descoberta d'esta parte do Novo Mundo". A fala de Vianna destaca a importância do espírito de associação para tal empresa. "É sem dúvida do espírito de associação assim extreme que tem resultado o adiantamento rápido e seguras ciências, das artes e das letras" (VIANNA, 1973: 2). Prossegue afirmando que: "o espírito de associação [tem, pois] derramado também entre nós aqueles benefícios que soa difundir por toda a parte em que ele se ostenta puro e limpo dos abusos, que nascem principalmente da liga sórdida das tramas tenebrosas da política" (VIANNA, 1973: 2).

O futuro marquês de Sapucaí refere-se ao fato do IHGB ter sido fundado no período regencial, momento conturbado da política nacional. Estamos lidando, portanto, com um discurso compromissado. O "espírito de associação", destacado por Vianna, pretende evidenciar que a união é uma poderosa arma de combate à fragmentação política (MATTOS, 2004: 235). Destaca-se que na Europa também existiram essas Sociedades Literárias, recomendadas na passagem do século XVI para o XVII pelo filósofo e Chanceler Britânico, Francis Bacon, e que outro filósofo, orador de Roma (que possivelmente seria Cícero), dizia que o estudo "não quer a solidão; deseja companheiros nos trabalhos para ensinar ou aprender, ouvir ou discorrer" (VIANNA, 1973: 2). Interessante é que os pensadores que também exerciam as funções de políticos, perfil dos associados do IHGB, são sempre lembrados para dar mais força aos argumentos. A associação de eruditos seria uma espécie de projeto pedagógico essencial, segundo o exemplo europeu, para promover os estudos científicos e estimular as artes e as letras no país.

Em 1841, o espírito de associação já era alimentado pelo visconde de $\mathrm{S}$. Leopoldo, que após ter destacado a importância da proteção imperial, revela uma 
questão muito importante na retórica oitocentista. "Quando a Providência se apraz de dar aos povos tais monarcas" lega-se um grande estímulo à posteridade. Há uma comparação com Carlos Magno, criador da escola palatina, que utiliza a religião para desencadear um efeito retórico, já que tem o propósito de relacionar a antiga instituição criada pelo rei carolíngio com o Instituto Histórico, ambos sob a égide celestial. Após o nome do soberano francês é posto entre parênteses: "Leão III lhe cinge em Roma o diadema dos Césares, e o primeiro se prostra ante ele; à esta cena retumba a igreja de $\mathrm{S}$. Pedro com as aclamações de um povo abatido, nos desvarios do orgulho extasiado como a imagem do seu antigo esplendor". (SÃO LEOPOLDO, 1841: 519)

Em seguida, seguem-se os elogios ao monarca medieval: "grande homem, grande rei, grande legislador, lançado como brilhante exceção em meio de um século bárbaro e de trevas, ia resfolegar de tanta lida na sua favorecida Academia Aulica...”. Após citar os feitos da dinastia dos Braganças, em termos de proteção às ciências, volta aos sábios da Antiguidade:

Se fosse conhecido dos antigos esse nosso sistema de associações literárias, se florescessem em Roma academias, Horácio, para não poluir a sisuda companhia do seu amigo Virgílio, de boamente riscaria de seus versos algumas obscenidades; Lucrécio, para não desmerecer a honra de cônscio de Cícero, só haveria conservado no seu poema traços os sublimes, com que se mostra tão grande pintor, e teria suprimido aqueles, nos quais em frios versos prosaicos dá lições de ateísmo: isto é, nos quais se esforça por tirar o freio ao perverso, que triunfa, e a consolação ao virtuoso infeliz (SÃO LEOPOLDO, 1841:519-521).

Passagem curiosa. São Leopoldo e outros oradores sempre se valeram do exemplo dos antigos, para reforçar a importância da missão dos eruditos, mas nesse momento, discute com os clássicos. Afirma que se estes tivessem um "sistema de associações literárias" protegido por um soberano como o nosso, ou melhor, um monarca escolhido pela Providência, seriam ainda mais virtuosos. Horácio riscaria as obscenidades de seus versos e, Cícero, teria "suprimido" as lições de ateísmo de suas máximas.

A ideia de que a religião civiliza estava de acordo com os argumentos criados no próprio circuito europeu de onde as ideias eram capturadas. Em 1756, Mirabeau, afirma 
que a religião tornou a civilização possível: "a religião, longe de ser excluída pelas 'virtudes sociais' ou pela 'moral natural', é considerada por Mirabeau como o 'principal móvel' da civilização, ela mesma assimilada à sociabilidade" (apud STAROBINSKI, 2001: 14). O Dicionário Universal (Trévoux) de 1771 descreve que “a religião é incontestavelmente o primeiro e o mais útil freio da humanidade; é o primeiro móvel da civilização" (STAROBINSKI, 2001: 12), porque liberta os instintos humanos da barbárie, da violência, e de outros costumes tidos como rudimentares. E é por isso também que o visconde de São Leopoldo, no final da passagem citada, assegura que o ateísmo dos antigos freava a felicidade e o progresso.

As ideias emanavam deste vocabulário e, as que vinham de fora, nele tentavam se enquadrar. Uma casa composta por muitos clérigos e religiosos e um Estado protetor da religião católica liderado por um monarca que carregava toda uma simbologia religiosa, explica o enquadramento do discurso ao sentimento cristão. Isso dá corpo a uma das máximas da teoria da argumentação: "é em função de um auditório que qualquer argumentação se desenvolve" (PERELMAN e OLBRECHTS-TYTECA, 2005: 6). Na Retórica à Herênio, obra clássica, mas de autor ainda desconhecido , afirma que uma narração só alcançará verossimilhança quando respeitar às circunstâncias em que está inserida (Retórica à Herênio, 2005: 69). A comunicação, desta forma, promove um sentido não apenas no que é proferido no discurso, mas no relacionamento entre a vivência e a expectativa do ouvinte. Trata-se de uma experiência estética de recepção que desemboca em significados reconhecidos no mundo social, possibilitando a permanência ou a mudança das significações (JAUSS, 1979: 50).

No caso brasileiro, religião e ciência juntas promoviam a civilização e serviam de alicerce para os discursos que se edificavam no IHGB. No caso brasileiro a religião era defendida pela Constituição tendo uma grande presença no aparelho político e cultural do país. Por isso, ciência e religião não se refutavam. Trata-se de uma persuasão provocada pelos princípios mais difundidos em tal contexto. Horácio, Virgílio, Cícero, entre outros, não iriam se "poluir" com “obscenidades" e nem com "ateísmos" se tivessem uma proteção como tinham os nossos literatos dos oitocentos, envolvidos pelo manto da fé católica. Essa seria a constatação, segundo tais homens de letras, de que o Instituto estava provido de um caráter mais sublime que as associações dos antigos, argumento poderoso para dar maior incentivo aos membros.

Mas, nem por isso, os antigos deixaram de enriquecer a retórica dos "literatos" do Instituto Histórico. O visconde de São Leopoldo apropria-se da comparação, uma 
estratégia argumentativa milenar, ao dizer que os sábios eram "operários inteligentes", e, também, ao equiparar a associação carioca com as "mais ilustradas Academias da Europa", porque "tende para o aperfeiçoamento dos costumes e da civilização". Destaca um fator na Antiguidade que se assemelha ao Brasil de então, a existência de indígenas selvagens, pois as "nações antigas foram a um tempo polidas, brilhantes e bárbaras" (SÃO LEOPOLDO, 1842: 3). A nação brasileira também era, naquela ocasião, polida e bárbara. Mas o progresso, a exemplo do mundo grego, seria manifestado "pela conscienciosa observância das virtudes sociais", e pela descoberta de elementos fundamentais para a marcha da civilização. E quem descobriria esses elementos senão os sócios do IHGB. Permitam-nos uma citação mais longa:

A Grécia, ufana dos seus modelos na arte de historiar, os Herodotos, os Tucídedes, quantas vezes solicitados a formar de um mito tradicional uma narração irrefragável; dos seus oradores, os Isocrates, os Demosthemes, de cujas palavras, como de cadeias de ouro, pendiam seus imensos ouvintes; absorta nas sublimes inspirações de Sócrates sobre a moral e sobre a existência de Deus, em recompensa que recebeu a cicuta; elevada na grandeza, na extensão do prodigioso engenho de Aristóteles; na eloquência e elevação de pensamentos do divino Platão; nos primores da original poesia de Homero, de Esquiles, de Sófoles, e de Píndaro; ornadas nos nomes venerandos de Aristides, de Focion; ditando lições de sagaz política em Péricles, ambicionando o soberano poder, de que Miltiades logrou de fato, ao qual Temístocles em vão aspirou (SÃO LEOPOLDO, 1842:3).

Ao findar dessas citações, o visconde de São Leopoldo diz que Atenas, "centro das mais célebres escolas", proclamou que "aqui [graças a todos esses sábios] sabe-se perfeitamente definir a virtude" (SÃO LEOPOLDO, 1842: 3). Em nosso caso a Corte seria este "centro" por abrigar o próprio Instituto, além do Colégio Pedro II e do Arquivo Imperial; a definição legítima e virtuosa da sociedade estaria ali, como na Grécia, ao lado do poder cultural e político. Depois de citar tantos sábios do mundo grego, no mesmo parágrafo, São Leopoldo dita à missão dos membros no projeto pedagógico traçado para se atingir a civilização: resgatar vestígios dos povos civilizados; salvar os monumentos fidedignos para a História e a Geografia do país; propagar para as "classes menos ilustradas" o conhecimento ofuscado sobre o período colonial; e consagrar os altares a virtude, como fizeram os antigos em Atenas. 
Uma comparação cativante, já que relacionava seus confrades com os grandes nomes da tradição clássica perpetuados pela história e que tinham a mesma missão de trazer a virtude à consciência de todos. A Antiguidade estava provida de homens que se dedicavam a arte de historiar; o que se tentava provar é que o Brasil também tinha os seus. A comparação pode servir de prova retórica muito mais eficiente que a analogia ou a semelhança, pois é invocada para constatar um fato (PERELMAN e OLBRECHTS-TYTECA, 2005:274-275). É irrefragável a importância dos sábios do mundo antigo para a cultura ocidental, portanto, colocar os sócios em uma situação em que os relacionava com os antigos mestres (na difusão da educação e propagação da virtude), serviria para provocar neles um sentimento sublime de relevância, instigando o desejo de esmero e dedicação ao trabalho. E é interessante destacar que quando o exemplo fosse útil para o que se queria provar, na maioria dos casos, não importaria a cultura, ou a religião. Como vimos, São Leopoldo repudiou o "ateísmo" e as "obscenidades" dos antigos, agora, estes mesmos pensadores o inspiram. A retórica é o manejo das conformidades.

Outro nível de comparação é feito pelo visconde de São Leopoldo. Assinala que subirá ainda mais a fama da nação, “a expedição confiada a um intrépido nosso cônscio, em pesquisa de inculcados monumentos". Essa expedição será liderada, anos à frente, pelo cônego Benigno José de Carvalho e Cunha que pretendia encontrar uma antiguíssima cidade abandonada no interior da Bahia a partir de especulações da época embasadas em um documento datado de 1754. Tratava-se da comprovação da existência de antigas populações nórdicas no Brasil. O presidente do Instituto afirma que a nação brasileira terá sua fama mais exaltada se obtiver êxito,

como ora, no México, as ruínas de Mitla e de Palenque atestam a existência desse nosso continente, e a inteira desaparição de nações florentes, as quais deixaram vestígios de uma antiguidade, não menos venerável, de uma civilização talvez contemporâneas a do Egito e a da Índia (SÃO LEOPOLDO, 1841: 521).

Os letrados do IHGB são comparados aos grandes pensadores gregos e romanos, afirmando-se que suas obras teriam o mesmo teor civilizacional daqueles. Entretanto, outro aspecto é comparado: o objeto a ser investigado. Ao comparar as possíveis descobertas em terras brasileiras aos achados arqueológicos das grandes civilizações, 
pretendia-se surtir um efeito de nobreza e esplendor da pesquisa que contribuiria para erguer a nação brasileira ao rol das nações mais civilizadas do planeta. Como já foi ressaltado, a "argumentação não poderia ir muito longe sem recorrer a comparação, nas quais se cotejam vários objetos para avaliá-los um em relação ao outro" (PERELMAN e OLBRECHTS-TYTECA, 2005: 274).

\section{Conclusão}

Até aqui, foi possível perceber que se os discursos visavam esclarecer que o IHGB estava à frente das outras instituições capazes de promover o progresso da nação, isso se daria pelo vigor intelectual de seus membros. A missão do Instituto não era apenas a de coligir documentos para a História nacional, mas também, a de evidenciar nas mentes e nos corações dos brasileiros sua aptidão e dedicação a tal tarefa. Criar uma perspectiva unívoca da nação brasileira sob a égide do Estado e do Instituto Histórico era a principal meta.

O esforço da investigação tem como fim sanar as dúvidas sobre o passado nacional e colocar a nação brasileira no rol das mais civilizadas do mundo. Como destaca Charles Peirce, considerado por muitos como o pai da semiótica, é o fím de toda e qualquer investigação “o acordo de opiniões” (PEIRCE, 1979: 77). Sem dúvida seria o fim da persuasão também. Deste modo, construindo um pensamento unívoco sobre o que é ser brasileiro, compromissado com a centralização do poder na monarquia constitucional, o incentivo a pesquisa era útil para construir os novos heróis da nação. Os guardiões da memória nacional. É como o reforço de argumento usado pelo próprio visconde de São Leopoldo, ao destacar que os sábios se decepcionariam se não existissem novas descobertas para fazer. Cita Plutarco: "lamentava o guerreiro que não houvesse mais mundos para subjugar" (SÃO LEOPOLDO, 1841: 518).

\section{Fontes}

$67^{\text {a }}$ Sessão em 6 de Julho de 1841 (1841). Revista do Instituto Histórico e Geográfico Brasileiro. Tomo III, pp. 349-354. Disponível eml: http://www.ihgb.org.br/rihgb/rihgb1841t0003c.pdf. Acesso em: 13 de jul 2011.

$103^{\text {a }}$ Sessão em 20 de Abril de 1843 (1885). In: R.IHGB, Rio de Janeiro, 3 ed.,Tomo 5. pp. 260-262 Disponível em http://www.ihgb.org.br/rihgb/rihgb1843t0005c.pdf. Acesso em: 20 de ago. 2011. 
$178^{a}$ Sessão em 16 de setembro de 1847 (1869). In: Revista do Instituto Histórico e Geográfico Brasileiro, 2 ed., Rio de Janeiro, Tomo IX. pp. 442-444. Disponível em http://www.ihgb.org.br/rihgb/rihgb1847t0009c.pdf. Acesso em: 22 de jun. 2011.

$212^{\text {a }}$ Sessão em 15 de Dezembro de 1849 (1973). In: Revista do Instituto Histórico e Geográfico Brasileiro. Rio de Janeiro, 2 ed., Tomo Quinto, v. 12. pp. 550-557. Disponível em http://www.ihgb.org.br/rihgb/rihgb1849t0012c.pdf. Acesso em: 22 de jan. 2012.

BARBOSA, Januário da Cunha (1885 [1843]). Relatório dos trabalhos acadêmicos do Instituto no quinto ano social. In: Revista do Instituto Histórico e Geográfico Brasileiro. Rio de Janeiro, Tomo 5, vol. 5, pp. 04-29. Disponível em http://www.ihgb.org.br/rihgb/rihgb1843t0005c.pdf. Acesso em: 20 de ago 2011.

HOMEM, Francisco de Salles Torres (1843). Introdução. In: Revista Minerva Brasiliense: jornal de sciencias, letras e arte. Rio de Janeiro, $\mathrm{n} 1$, v.1, $1^{\circ}$ de novembro. pp. 01-05.

LAGOS, Manoel Ferreira (1916 [1840]). Elogio histórico ao padre mestre fr. José Mariano da Conceição Velloso. In: Revista do Instituto Histórico e Geográfico Brasileiro. Rio de Janeiro, 3 ed. Tomo II. pp. 610-621. (1840). Disponível em http://www.ihgb.org.br/rihgb/rihgb1840t0002c.pdf. Acesso em: 10 de mar. 2011.

SÃO LEOPOLDO, Visconde de (1908 [1839]). Discurso de abertura. In: Revista do Instituto Histórico e Geográfico Brasileiro. Rio de Janeiro, 3 ed, Tomo I. pp. 209212. Disponível em http://www.ihgb.org.br/rihgb/rihgb1839t0001c.pdf. Acesso: 10 de mar. 2011.

(1841). Discurso de abertura. In: Revista do Instituto Histórico e Geográfico Brasileiro. Rio de Janeiro, Tomo III. pp. 517-521. Disponível em http://www.ihgb.org.br/rihgb/rihgb1841t0003c.pdf. Acesso em: 13 de jul 2011.

(1842). Discurso de abertura. In: Revista do Instituto Histórico e Geográfico Brasileiro. Rio de Janeiro. Tomo IV. pp. 01-04. Disponível em http://www.ihgb.org.br/rihgb/rihgb1842t0004c.pdf. Acesso em 15 de jun. 2011.

VIANNA, Cândido José de Araújo (1885). Discurso de abertura. In: Revista do Instituto Histórico e Geográfico Brasileiro. Rio de Janeiro, 3 ed., Tomo 5. pp. 01-03. Disponível em http://www.ihgb.org.br/rihgb/rihgb1843t0005c.pdf. Acesso em: 20 de agosto de 2011.

(1973). Discurso do Exm. Sr. Senador do Império e Vice-presidente do Instituto. In: Revista do Instituto Histórico e Geográfico Brasileiro. Rio de Janeiro, Tomo Sexto, Vol. 6. pp. 02-03. Disponível em http://www.ihgb.org.br/rihgb/rihgb1844t0006c.pdf. Acesso em: 23 de ago. 2011.

\section{Referências Bibliográficas}

AMOSSY, Ruth (2005). O ethos na intersecção das disciplinas: retórica, pragmática, sociologia dos campos. In: AMOSSY, Ruth (org.). Imagens de Si no Discurso. Trad: Dilson Ferreira da Cruz, Fabiana Komesu e Sírio Possenti. São Paulo: Contexto.

ARISTÓTELES (s/d). Arte Retórica e Poética. Rio de Janeiro: Tecnoprint.

CEZAR, Temístocles (2006). A retórica da nacionalidade de Varnhagen e o mundo antigo: o caso das origens dos Tupis. In: GUIMARÃES, Manoel Luiz Salgado (org.). Estudos Sobre Escrita da História. Rio de Janeiro: 7 Letras. 
CHARAUDEAU, Patrick (2009). Linguagem e Discurso: modos de organização. Organização de Aparecida Lino Pauliukonis e Ida Lúcia Machado. São Paulo: Contexto.

CHARAUDEAU, Patrick (2006) O Discurso Politico. Trad: Fabiana Komesu e Dilson Ferreira da Cruz. São Paulo: Contexto.

ENDERS, Armelle (2000). O Plutarco Brasileiro: a produção dos vultos nacionais no Segundo Reinado. Estudos Históricos, vol. 14, n. 25, pp. 40-62. Disponível em: http://www.cpdoc.fgv.br/revista/arq/283.pdf. Acesso em: 08 de jul. de 2009.

FAGUNDES, Raphael S (2012). O poder da persuasão: a retórica nas celebrações do Instituto Histórico e Geográfico Brasileiro. Dissertação (Mestrado em História). Universidade do Estado do Rio de Janeiro, Rio de Janeiro.

GUIMARÃES, Lucia Maria Paschoal (2011). Debaixo da Imediata Proteção Imperial: Instituto Histórico e Geográfico Brasileiro (1838-1889). 2a . ed. São Paulo: Annablume. e HOLTEN, Brigitte (1997). O Instituto Histórico e Geográfico Brasileiro, a Real Sociedade dos Antiquários do Norte e o Dr. Peter Wilhelm Lund: a suposta presença escandina na Terra de Santa Cruz e a ciência. Texto preparado para a entrega no Encontro de 1997 da Latin American Studies Association, Continental Plaza Hotel, Guadalajara, México, pp 01-11. Disponível em: http://168.96.200.17/ar/libros/guilholten.pdf. Acesso em: 20 de fev. 2012.

JAUSS, Hans Robert (1979). "A estética da recepção: colocações gerais". In: JAUSS, Hans Robert (et. al.) A Literatura e o Leitor: textos de estética da recepção. Coord. e trad: Luiz Costa Lima. Rio de Janeiro: Paz e Terra.

KOSELLECK, Reinhart (2006). Futuro Passado: Contribuição à semântica dos tempos históricos. Trad. Wilma Patrícia Maas. Rio de Janeiro: Contraponto.

MAINGUENEAU, Dominique (2001). O contexto da obra literária: enunciação, escritor, sociedade. Trad: Marina Appenzeller. $2^{\mathrm{a}}$. ed. São Paulo: Martins Fontes.

MATTOS, Ilmar Rohloff de (2004). O Tempo Saquarema. 5a. ed. São Paulo: Hucitec/INL.

MEYER, Michel (2007). Questões de Retórica: linguagem, razão e sedução. Trad: António Hall. Lisboa: Edições 70.

OLIVEIRA, Laura Nogueira (2007). A palavra empenhada: recursos retóricos na construção discursiva de Francisco Adolfo de Varnhagen. Tese (Doutorado em Letras). Universidade Federal de Minas Gerais. Belo Horizonte.

OLIVEIRA, Maria da Glória de (2010). Brasileiros ilustres no tribunal da posteridade: biografia, memória e experiência da história no Brasil oitocentista. Varia História, vol. 26, $\mathrm{n}^{\mathrm{o}}$ 43, pp 283-298. Disponível em: http://www.scielo.br/pdf/vh/v26n43/v26n43a15.pdf Acesso em: 27 de fev. 2015.

OLIVEIRA, Maria da Glória de (2010). Fazer história, escrever a história: sobre as figurações do historiador no Brasil oitocentista. Revista Brasileira de História, v. 30, n. 59, pp. 37-52. Disponível em: http://www.scielo.br/scielo.php?pid=S0102_01882010001000\&script=sci_ arttext\&tlng=en\#nota1. Acesso em: 30 de out 2010.

PEIRCE, Charles Sanders (1975). Semiótica e filosofia. 2a . ed. Trad: Octanny Silveira da Mota e Leonidas Hegenberg. São Paulo: Cutrix.

PERELMAN, Chaïm e OLBRECHTS-TYTECA, Lucie (2005). Tratado de Argumentação: a nova retórica. Trad: Maria Ermantina de Almeida Prado Galvão, São Paulo: Martins Fontes.

QUINTILIANO, M. Fabio (1788). Instituiçoens Oratórias. Trad: Jeronymo Soares Barbosa. Tomo Primeiro, Coimbra: Imprensa Real da Universidade. 
RETÓRICA à Herênio (2005) Trad. e Int: Ana Paula Celestino Faria e Adriana Seabra. São Paulo: Hedra.

STAROBINSKI, Jean (2001). As Máscaras da Civilização: ensaios. Tradução de Maria Lúcia Machado. São Paulo: Cia das Letras.

TURIN, Rodrigo (2009). Uma nobre, difícil e útil empresa: o ethos do historiador oitocentista. História da historiografia, n 2, março, pp. 12-28.

Artigo recebido em 25 de março de 2015.

Aprovado em 27 de maio de 2016.

DOI: $10.12957 /$ intellectus.2016.20946 